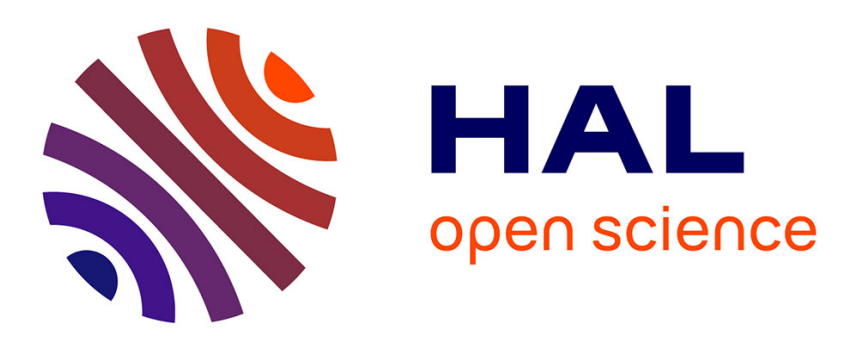

\title{
Use of Py-GC/MS and PCFC to characterize the surface modification of flax fibres
}

G. Dorez, B. Otazaghine, A. Taguet, L. Ferry, J. M. Lopez-Cuesta

\section{To cite this version:}

G. Dorez, B. Otazaghine, A. Taguet, L. Ferry, J. M. Lopez-Cuesta. Use of Py-GC/MS and PCFC to characterize the surface modification of flax fibres. Journal of Analytical and Applied Pyrolysis, 2014, 105, pp.122-130. 10.1016/j.jaap.2013.10.011 . hal-02914354

\section{HAL Id: hal-02914354 \\ https://hal.science/hal-02914354}

Submitted on 1 Jun 2021

HAL is a multi-disciplinary open access archive for the deposit and dissemination of scientific research documents, whether they are published or not. The documents may come from teaching and research institutions in France or abroad, or from public or private research centers.
L'archive ouverte pluridisciplinaire HAL, est destinée au dépôt et à la diffusion de documents scientifiques de niveau recherche, publiés ou non, émanant des établissements d'enseignement et de recherche français ou étrangers, des laboratoires publics ou privés. 


\title{
Use of Py-GC/MS and PCFC to characterize the surface modification of flax fibres
}

\author{
G. Dorez, B. Otazaghine*, A. Taguet, L. Ferry, J.M. Lopez-Cuesta \\ Centre de Recherche CMGD, Ecole des Mines d'Alès, 6 Avenue de Clavières, F-30319 Ales Cedex, France
}

\begin{abstract}
A B S T R A C T
Surface modification of flax fibres with a phosphorous agent in a solvent process have been originally evaluated through thermal degradation using Pyrolysis Combustion Flow Calorimeter and PyrolysisGas Chromatography/Mass Spectrometry. It has been highlighted that these techniques are particularly sensitive to the presence of the phosphonated grafting agent on natural fibres. After treatment, octadecylphosphonic acid (ODPA) was found to be covalently grafted on the flax fibres at a rate of almost $5 \%$. For a better comprehension of the interactions between the phosphonic group and flax, the reactivity of the phosphonic acid function of ODPA with the main components of fibres was assessed. The results showed that ODPA reacts strongly with lignin and at a lower degree with xylan (model for hemicellulose) whereas no reaction with cellulose was evidenced.
\end{abstract}

Keywords:

Flax

Surface modification

Py-GC/MS

PCFC

Octadecylphosphonic acid

Cellulose

Xylan

Lignin

\section{Introduction}

In recent years, the use of natural fibres as reinforcement in polymers has increased considerably due to their low cost, renewability, biodegradability, low density, good mechanical properties. However, their hydrophilic nature leads to a poor compatibility with most polymers especially with non-polar polymers such as PP and PE [1,2]. Moreover, natural fibres contain water that can weaken the interfacial adhesion in the composite because of the sensitivity to moisture of some polymers (polyesters for instance). Hence, the improvement of the fibre-matrix compatibility is a key requirement to obtain good mechanical properties, which can be appropriately achieved by fibres surface modification $[3,4]$.

Fibre surface modification can be performed by different ways including physical treatments (gamma irradiation [5], electron beam [6], corona [7] and plasma [8]) and chemical treatments (alkali [9], silane [4], graft copolymerization [10], etc...). After treatment, surface modification can be highlighted by the use of various experimental techniques that have been classified in four categories by Belgacem et al. [11] direct (cat I) and indirect (cat II) techniques strictly limited to the surface, direct penetrating techniques (cat III), indirect bulk techniques (cat IV). Spectroscopic techniques, including X-ray photoelectron spectroscopy (XPS) (cat

\footnotetext{
* Corresponding author. Tel.: +33 04667856 69; fax: +33 0466785365 .

E-mail address: belkacem.otazaghine@mines-ales.fr (B. Otazaghine).
}

I), secondary ion mass spectroscopy (SIMS) (cat I), Fourier transform infrared spectroscopy (FTIR) (cat III) and solid state nuclear magnetic resonance (NMR) (cat IV), have been commonly use to characterize elemental compositions and chemical bonds at the fibre surface before and after modification [12-14]. Zafeiropoulos et al. [14] investigated modified and unmodified flax fibres with XPS, ToF-SIMS and ATR-FTIR techniques. The three spectroscopic methods reveal that the fibre surface chemistry has been altered after acetylation and stearic acid treatment. Pyrolysis-gas chromatography coupled mass spectroscopy (Py-GC/MS) (cat IV) has been also employed to characterize fibre treatment [15]. In this case, decomposition products of grafting agent are exploited as tracer of the chemical treatment. This technique was successfully used by some authors to characterize chemical modification of flax fibres [16,17]. Microscopic methods such as scanning electron microscopy (SEM) (cat III), transmission electron microscopy (TEM) (cat III) and atomic force microscopy (AFM) (cat I) are convenient techniques to characterize the morphology of the surface fibre before and after treatment $[11,12]$. SEM, often coupled with Energy Dispersive X-ray spectroscopy (EDX), enables to observe the topography of the fibre and to determine its elemental composition $[18,19]$. TEM is useful, when the size of the observed material is in the nanoscale range. AFM provides information on the morphology of the sample and allows to quantify the roughness and other properties of natural fibres [20]. Among the indirect techniques, most of them aim at assessing the evolution of surface properties of fibres after treatment. Hence, inverse gas chromatography IGC (cat II) has 
Table 1

Characterization techniques of surface modification.

\begin{tabular}{|c|c|c|c|c|}
\hline & $\begin{array}{l}\text { Spectroscopy \& chemical } \\
\text { analysis }\end{array}$ & Microscopy & Mechanical & Thermal \\
\hline Direct techniques limited to the surface (cat I) & $\begin{array}{l}\text { XPS [12,20,21] WAXS [11] SIMS } \\
{[21]}\end{array}$ & AFM $[12,18,20]$ & & \\
\hline Indirect techniques limited to the surface (cat II) & $\begin{array}{l}\text { Contact angle }[2,18,19] \text { IGC } \\
{[15-17]}\end{array}$ & & & \\
\hline Direct penetrating techniques (cat III) & FTIR $[13,21,22]$ EDX $[12,20]$ & $\begin{array}{l}\text { SEM }[12,13,20,22] \text { TEM } \\
{[20] \text { Confocal }} \\
\text { fluorescence } \\
\text { microscopy }[11]\end{array}$ & $\begin{array}{l}\text { Micromechanical test } \\
{[12,22,23]}\end{array}$ & \\
\hline Indirect bulk (cat IV) & $\begin{array}{l}\text { NMR }[12,20] \text { Elemental } \\
\text { analysis [19] }\end{array}$ & & $\begin{array}{l}\text { DMA [24] Flexural [14] } \\
\text { Tensile [14] }\end{array}$ & $\begin{array}{l}\text { TGA [14,24] DSC [13] } \\
\text { Py-GC/MS [25-27] }\end{array}$ \\
\hline
\end{tabular}

been frequently used to determine the dispersive component of surface energy and to evaluate the acid/base interface potential. Coupas et al. [21] have studied the grafting of maleic anhydride functionalized polypropylene (PP-g-MA) on cellulose fibres. They have determined that the PP-g-MA enhances the basic character of cellulose and modifies significantly the dispersive component of surface energy. Other kinds of treatments were studied with IGC, for example the alkalisation of the sisal fibres [22] or the grafting of silane on cellulose [23]. The surface energy could be determined by contact angle measurements too [23]. Cantero et al. [2] studied the influence of different treatments on the wettability of flax fibres/PP biocomposites. The dynamic contact angle was used for long flax fibres and PP matrix based on the Wilhelmy equation, and the capillary method was used for irregular flax pulp based on Washburn equation. For the two methods several liquids with different polarities have been used to determine the dispersive and polar components, and the surface energy was evaluated by the OwensWendt approach [24]. Surface modification may also impinge the thermal stability of fibres. Thermogravimetric analysis (TGA) (cat IV) was shown to be an adequate technique to highlight the change in decomposition pathway of benzoylated or acetylated sisal fibres [25] (Table 1).

In this work, the surface of flax fibres has been modified using octadecylphosphonic acid (ODPA). This molecule is composed of a fatty chain, which has no affinity with the natural fibres, and a functional head (phosphonic acid), which can potentially interact or react with the hydroxyl groups of the fibres. The phosphonated moiety was selected among others (silane, carboxylic acid, amine...) because it is believed to be more reactive in mild conditions. The surface modification of flax fibres has been investigated using an original combination of techniques based on thermal degradation: TGA, PCFC, Py-GC/MS. Pyrolysis techniques were used not only to study the occurrence of grafting but also to quantify its extent. These characterizations were completed by ${ }^{31} \mathrm{P}$ NMR and Scanning Electron Microscopy/Energy Dispersive X-ray (SEM/EDX).

\section{Experimental}

\subsection{Materials}

Flax fibres, fl (Fibras-S6D) were purchased from Fibres Recherche et Développement $\left(\mathrm{FRD}^{\circledR}\right)$. Octadecylphosphonic acid, ODPA (Specific polymers) and dimethyl(octadecyl)phosphonate,
Table 2

Chemical formula and $\mathrm{C} / \mathrm{O}$ atomic ratio of natural fibre components.

\begin{tabular}{llll}
\hline Components (\% in flax) & Chemical formula & C/O ratio \\
\hline Cellulose (80) & & $\left(\mathrm{C}_{6} \mathrm{H}_{10} \mathrm{O}_{5}\right)_{n}$ & 1.2 \\
Hemicelluloses (13) & Xylan & $\left(\mathrm{C}_{5} \mathrm{H}_{8} \mathrm{O}_{5}\right)_{n}$ & 1.0 \\
Lignin (2) & $\mathrm{H}$ (p-hydroxyphenyl) & $\left(\mathrm{C}_{9} \mathrm{H}_{10} \mathrm{O}_{2}\right)_{n}$ & 4.5 \\
& $\mathrm{G}$ (Guaiacyl) & $\left(\mathrm{C}_{10} \mathrm{H}_{12} \mathrm{O}_{3}\right)_{n}$ & 3.3 \\
& $\mathrm{~S}$ (Syringyl) & $\left(\mathrm{C}_{11} \mathrm{H}_{14} \mathrm{O}_{4}\right)_{n}$ & 2.75 \\
\hline
\end{tabular}

DMODP (Specific polymers) were used as treatment agents. Cellulose Arbocel B 600, cel (Rettenmaier \& Söhne), xylan extracted from beechwood, xyl (Sigma-Aldrich) and an organosolv lignin, lig kindly supplied by the Centre de Mise en Forme des Matériaux (CEMEF-Mines ParisTech at Sophia Antipolis, France) were used as model of the main components of lignocellulosic fibres. Table 2 lists the chemical formula and $\mathrm{C} / \mathrm{O}$ ratio of these molecules.

\subsection{Fibres treatments}

\subsubsection{Pretreatment of the flax fibres}

Before chemical modification with the functionalized agents, the flax fibres were pretreated with ethanol to remove waxes and pectin which ensure the cohesion of the flax beam [19].

In a one-necked round-bottom flask $(250 \mathrm{~mL})$ equipped with a condenser, $2 \mathrm{~g}$ of flax fibres and $80 \mathrm{~mL}$ of ethanol were introduced. The mixture was heated under reflux for $5 \mathrm{~h}$ with vigorous magnetic stirring. The liquid phase was then eliminated and the flax fibres were washed three times with ethanol and dried at room temperature. The sample designation of the pretreated fibres is Tfl.

\subsubsection{Chemical modification of the flax fibres by ODPA and DMODP}

In a one-necked round-bottom flask $(250 \mathrm{~mL})$ equipped with a condenser, $2 \mathrm{~g}$ of pretreated flax fibres, $0.2 \mathrm{~g}$ of the treatment agent and $80 \mathrm{~mL}$ of ethanol were introduced. The mixture was heated under reflux for $5 \mathrm{~h}$ with vigorous magnetic stirring. The liquid phase was then eliminated and the treated flax fibres were washed three times with ethanol and dried at room temperature. The samples are noted Tfl/ODPA and Tfl/DMODP. The cellulose, xylan and lignin samples were treated with the same protocol than the flax fibres and noted cel/ODPA, xyl ODPA, and lig/ODPA, but no pretreatment was required.

Table 3

EDX analysis of untreated and pretreated fibres.

\begin{tabular}{|c|c|c|c|c|c|c|c|}
\hline & & C (wt.\%) & $\mathrm{O}(\mathrm{wt} . \%)$ & $\mathrm{Ca}(\mathrm{wt} . \%)$ & K (wt.\%) & $\mathrm{Mg}$ (wt.\%) & Ratio $\mathrm{C} / \mathrm{O}$ \\
\hline $\mathrm{fl}$ & & 46.5 & 53.0 & 0.5 & 0.0 & 0.0 & 0.9 \\
\hline \multirow[t]{2}{*}{ Tfl } & Crust & 59.3 & 38.7 & 1.4 & 0.4 & 0.0 & 1.5 \\
\hline & Fibre & 49.2 & 50.5 & 0.1 & 0.1 & 0.0 & 1.0 \\
\hline
\end{tabular}



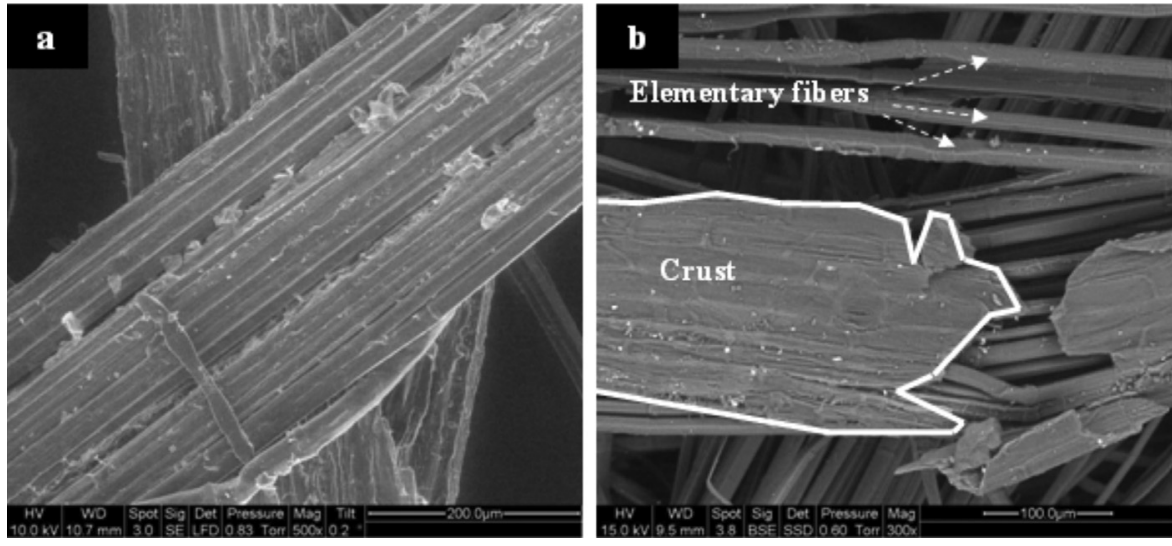

Fig. 1. SEM micrographs of flax fibres: (a) untreated, (b) pretreated.

\subsubsection{Soxhlet extraction procedure}

After chemical modification, fibres were submitted to a $24 \mathrm{~h}$ soxhlet extraction with ethanol, in order to remove the entire unreacted treatment agent. Then, they were dried at room temperature, and noted Tfl/ODPA sox.

\subsection{Characterizations}

\subsubsection{Thermogravimetric analysis (TGA)}

A Perkin Elmer Pyris-1 Thermogravimetric apparatus was used to analyze the thermal degradation of treatment agents and treated fibres. Sample weights of around $10 \mathrm{mg}$ were heated from 50 to $600^{\circ} \mathrm{C}$ at a heating rate of $10^{\circ} \mathrm{C} / \mathrm{min}$ under nitrogen atmosphere. Residual weight at $600^{\circ} \mathrm{C}\left(\operatorname{Res}_{600}\right)$ and maximum degradation temperature (Tdeg) were determined.

\subsubsection{Pyrolysis combustion flow calorimeter (PCFC)}

Pyrolysis combustion flow calorimeter is a technique developed by Lyon and Walter [26] to investigate fire behaviour of samples at microscopic scale. Sample weights of around $2 \mathrm{mg}$ are pyrolyzed at $1{ }^{\circ} \mathrm{C} / \mathrm{s}$ and the degradation products are transported by inert gas flux. Then, they are mixed with oxygen before entering a combustor at $900{ }^{\circ} \mathrm{C}$ where the products are completely oxidized. The heat release rate is measured as a function of temperature. The values of peak of release rate (pHRR), temperature of pHRR (Tdeg), and the Effective heat of combustion (EHC), which correspond to the heat release per gram of mass loss, were determined.
Table 4

TGA and PCFC values for pretreated flax (Tfl), treated flax (Tfl/ODPA) and ODPA.

\begin{tabular}{|c|c|c|c|c|c|}
\hline \multirow[t]{2}{*}{ Samples } & \multicolumn{3}{|l|}{ PCFC } & \multicolumn{2}{|l|}{ TGA } \\
\hline & $\operatorname{Tdeg}\left({ }^{\circ} \mathrm{C}\right)$ & pHRR (W/g) & $\mathrm{EHC}(\mathrm{kJ} / \mathrm{g})$ & $\operatorname{Res}_{600}(\%)$ & $\operatorname{Tdeg}\left({ }^{\circ} \mathrm{C}\right)$ \\
\hline ODPA & 487 & 588 & 34.3 & 21.0 & 457 \\
\hline Tfl & 371 & 132 & 9.5 & 21.7 & 381 \\
\hline Tfl/ODPA & 370 & 122 & 10.6 & 19.1 & 375 \\
\hline
\end{tabular}

\subsection{3. $P y-G C / M S$}

A Pyroprobe 5000 pyrolyzer (CDS analytical) was used to flash pyrolyze the samples in a helium environment. This pyrolyzer is supplied with an electrically heated platinum filament. One coil probe enables the pyrolysis of samples $(<1 \mathrm{mg})$ placed in a quartz tube between two pieces of rockwool. The sample was heated at $900{ }^{\circ} \mathrm{C}$. The temperature was held for $15 \mathrm{~s}$ then the gases were drawn to the gas chromatograph for $5 \mathrm{~min}$. The pyroprobe 5000 is interfaced to a 450-GC chromatograph (Varian) by means of a chamber heated at $270^{\circ} \mathrm{C}$. In the oven the initial temperature of $70^{\circ} \mathrm{C}$ was raised to $250^{\circ} \mathrm{C}$ at $10^{\circ} \mathrm{C} / \mathrm{min}$. The column is a Varian Vf$5 \mathrm{~ms}$ capillary column $(30 \mathrm{~m} \times 0.25 \mathrm{~mm}$; thickness $=0.25 \mu \mathrm{m})$ and helium ( $1 \mathrm{~L} / \mathrm{min})$ was used as the carrier gas, a split ratio was set to $1: 50$. The gases were introduced from the GC transfer line to the ion trap analyzer of the 240-MS mass spectrometer (Varian) through the direct-coupled capillary column. Chromatograms presented in this work are extracted ion chromatogram (EIC) at $\mathrm{m} / \mathrm{z}$ 56. In a first time, radical ions at $m / z 55,56$ and 57, corresponding to alkyls and alkenes compounds obtained during ODPA decomposition, were tested. Radical ion at $m / z 56$ (characteristic of $\mathrm{C}_{4} \mathrm{H}_{8}{ }^{+\bullet}$
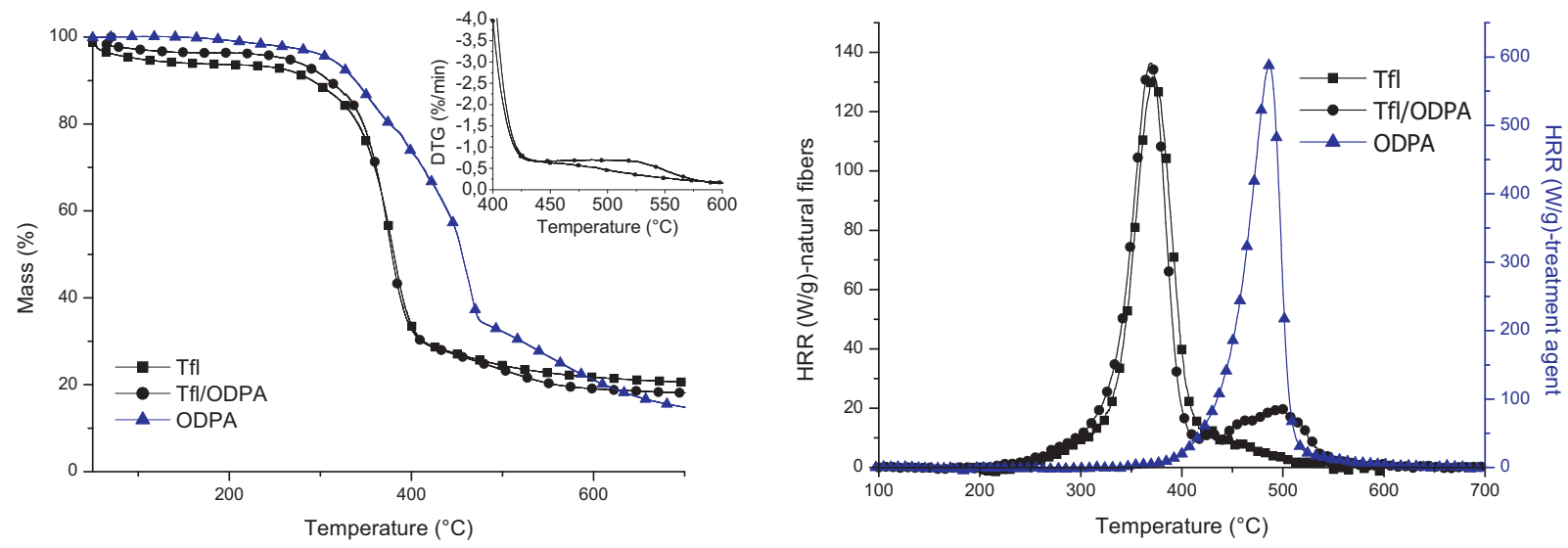

Fig. 2. TGA (left) and PCFC (right) curves of respectively pretreated flax (Tfl), treated flax (Tfl/ODPA) and ODPA. 

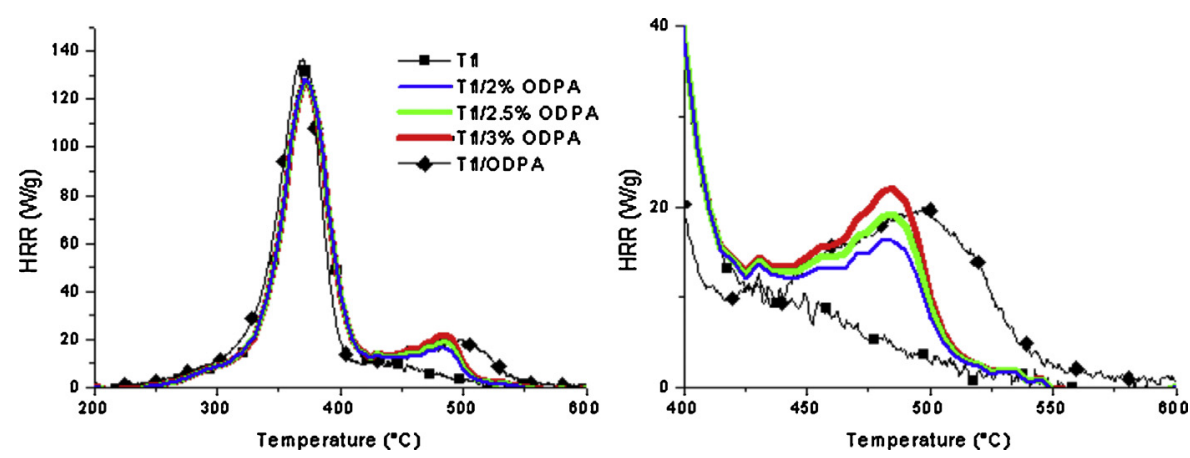

Fig. 3. Experimetal (Tfl and Tfl/ODPA) and theoretical (Tfl/2\%ODPA, Tfl/2.5\%ODPA and Tfl/3\%ODPA) curves of HRR versus temperature for flax fibres treated with ODPA.

from n-alkenes) has been chosen because of the better intensities obtained for the chromatogram peaks.

\subsubsection{Solid state ${ }^{31}$ P NMR analyzes}

Solid state ${ }^{31}$ P NMR was carried out using a Bruker DRX 300 spectrometer. The experimental conditions for recording ${ }^{31} \mathrm{P}$ NMR were as follow: CP-MAS (cross polymerization magic angle spinning), pulse delay (5 s) and frequency (121.49 MHz).

\subsubsection{Elemental analyzes}

For phosphorus elemental analysis, the samples were dissolved in acid solution and analyzed by inductively coupled plasma atomic emission spectroscopy (ICP AES). A Thermo Finnigan Flash EA 112 Series was used for the elemental analysis of carbon, oxygen and hydrogen. The carbon and hydrogen amounts were determined after combustion at $940^{\circ} \mathrm{C}$. The oxygen amount was measured after combustion at $1000^{\circ} \mathrm{C}$.

\subsubsection{Scanning electron microscope (SEM)}

The micrographs were obtained with an environmental scanning electron microscope (FEI Quanta SEM) equipped with a scanning transmission electron microscopy detector (STEM). Micrographs were obtained with high vacuum at a voltage between 10 and $15 \mathrm{kV}$, with a spot size of 3-3.8 $\mathrm{nm}$ and a working distance

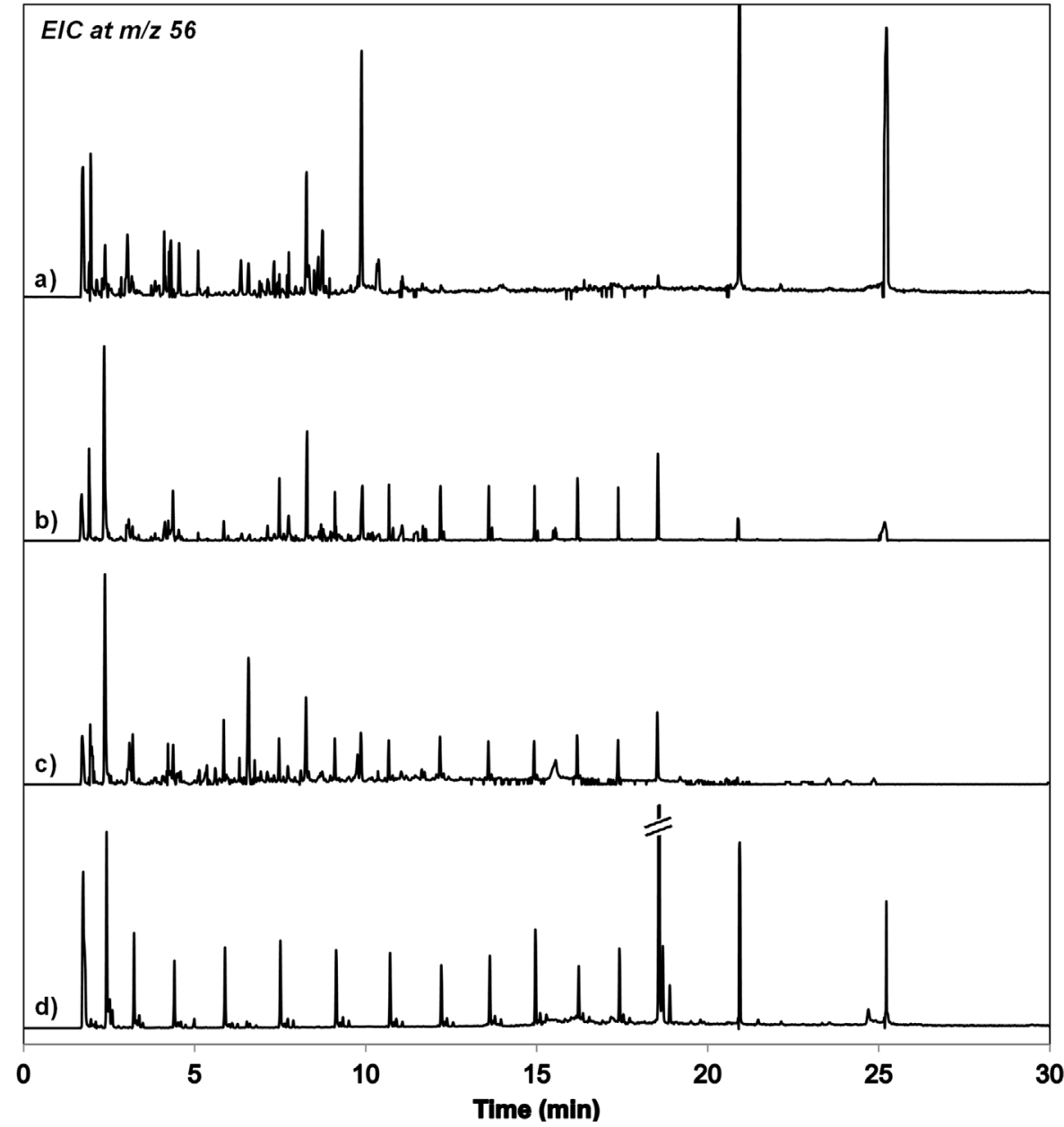

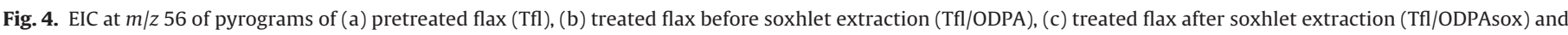
(d) ODPA. 
between 9.5 and $10.7 \mathrm{~mm}$. Elemental analysis of phosphorus at the fibre surface was performed by Energy Dispersive X-Ray spectroscopy (EDX) analysis using Oxford INCA Energy system and a detector of $133 \mathrm{eV}$ resolution.

\section{Results}

\subsection{Influence of the pretreatment}

Natural fibres are composed of elementary fibres assembled in bundles, as shown in Fig. 1a. These bundles are maintained together with polysaccharides and waxes [27]. In order to get better mechanical performance in fibre reinforced composites, separation of individual fibres should be achieved [19]. The pretreatment usually carried out is an alkali-treatment that removes waxes, lignin and hemicelluloses. Thus, this treatment induces a denaturation of the fibres (destructuring, swelling, surface degradation...). In this study, a pretreatment in ethanol was performed to separate the flax bundles in elementary fibres by the elimination of polysaccharides and waxes. This treatment was supposed to be softer than alkali-treatment. Fig. 1b does not reveal any destructuring or surface degradation. A piece of "crust" around elementary fibres is also observed (Fig. 1). EDX analysis (Table 3) shows an evolution of the composition between untreated and treated fibres. An increase of the $\mathrm{C} / \mathrm{O}$ ratio is observed after ethanol treatment. This result may indicate that, the pretreatment eliminates a part of the cellulose and xylan, whereas lignins are not eliminated especially at the
Table 5

Results of elemental analyses for Tfl, Tfl/ODPA and Tfl/ODPAsox.

\begin{tabular}{llllll}
\hline Sample & $\mathrm{C}($ wt.\%) & $\mathrm{O}($ wt.\%) & $\mathrm{H}($ wt.\%) & $\mathrm{P}$ (wt.\%) & ODPA (wt.\%) \\
\hline Tfl & 41.2 & 39.5 & 7.3 & 0 & 0 \\
Tfl/ODPA & 43.3 & 37.8 & 7.9 & 0.52 & $5.61 \%$ \\
Tfl/ODPAsox & nd & nd & nd & 0.40 & $4.32 \%$ \\
\hline
\end{tabular}

fibre surface (Tables 2 and 3). In the case of treated fibres, analyses were performed on elementary fibres and on the "crust". The results show a higher concentration of carbon and mineral salts for crust than for elementary fibres, which proves the difference of structure and composition between the two.

The pretreatment induces a splitting of the fibre bundle and the formation of elementary fibres. Therefore the surface of fibres available for the chemical treatment increases. Subsequently, a pretreatment of the flax fibres has been realized before each chemical treatment.

\subsection{Grafting of ODPA on flax fibres (TGA, PCFC, Py GC-MS)}

The ODPA treatment agent decomposes between 350 and $450{ }^{\circ} \mathrm{C}$ forming a large residue over $700{ }^{\circ} \mathrm{C}$. However, Fig. 2a reveals that the thermal behaviour of flax (Tfl) and treated flax (Tfl/ODPA) are very similar with a main degradation step at $375^{\circ} \mathrm{C}$. There is no noticeable influence of ODPA agent on the thermal degradation of flax. However, it could be noted that ODPA treated flax exhibits a minor additional degradation step around $530^{\circ} \mathrm{C}$.

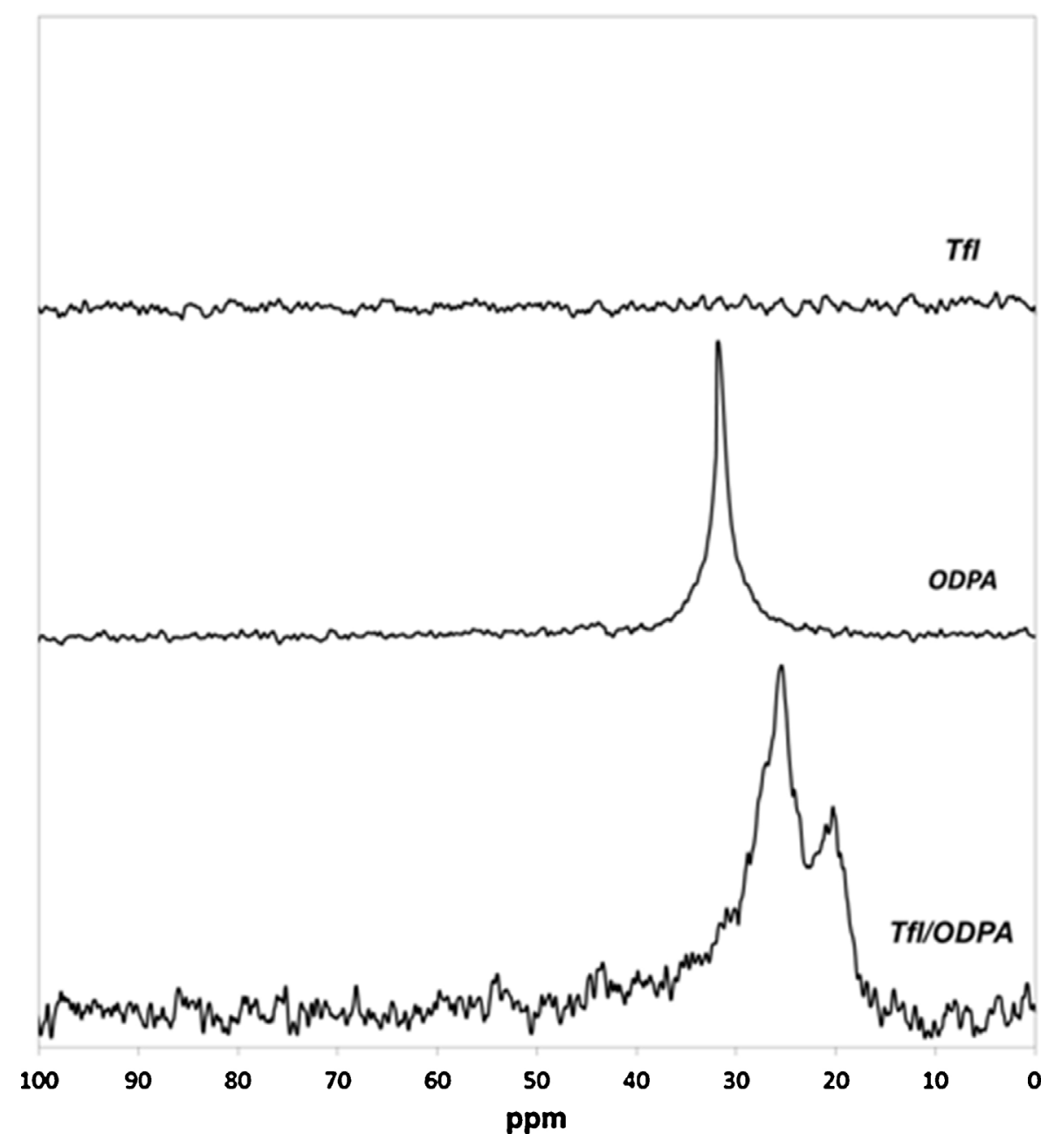

Fig. 5. Solid state 31P NMR of Tfl, Tfl/ODPA and ODPA. 


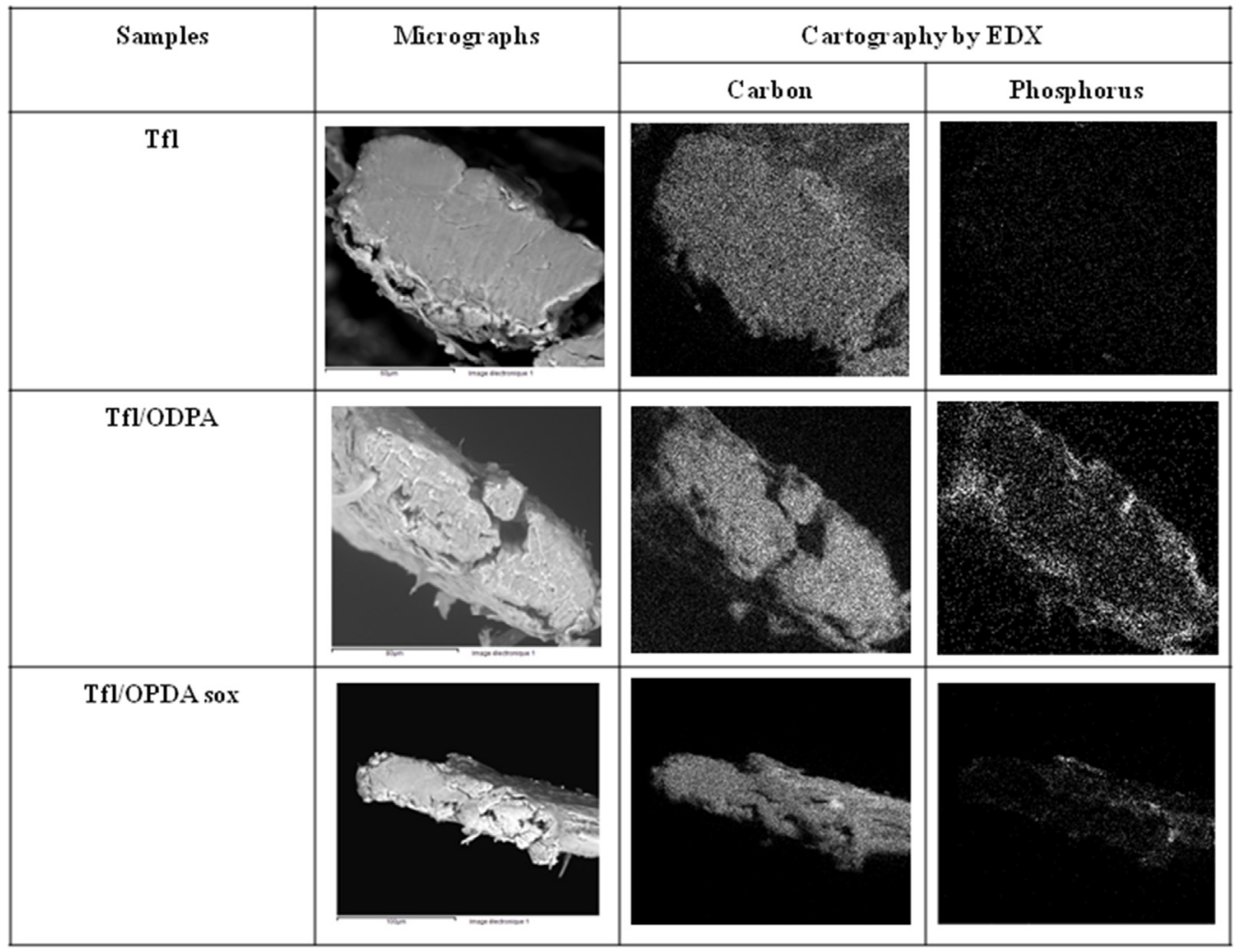

Fig. 6. EDX cartography of Tfl fibre, Tfl/ODPA fibre before and after soxhlet.
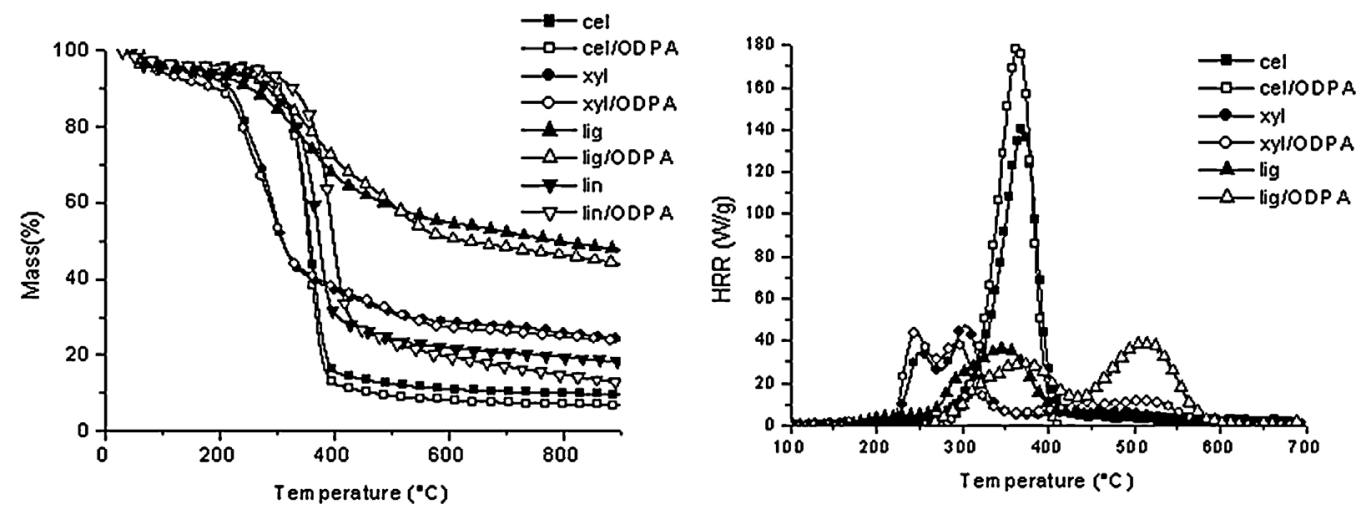

Fig. 7. TGA and PCFC curves of cellulose, xylan and lignin treated with ODPA.

The decomposition ranges in PCFC are consistent with those obtained in TGA (Fig. 2b compared to Fig. 2a). But PCFC measures the energy released by the combustion of the pyrolysis products, and it is more sensitive to the presence of surface modifier than TGA especially for ODPA that is mainly composed of a hydrocarbon chain. ODPA exhibits a high peak of HRR in PCFC around $500^{\circ} \mathrm{C}$ (Fig. 2b).
Moreover, Table 4 indicates that the heat of combustion of the ODPA is much higher than that of flax fibre (Tfl). Hence, in the case of Tfl/ODPA, a second peak appears at high temperature (around $500^{\circ} \mathrm{C}$ ), in the same region than that observed for pure ODPA. This peak corresponds to the degradation of the phosphonated molecule and is a proof of the presence of ODPA on the treated flax fibres.

Table 6

TGA and PCFC values of cellulose, xylan and lignin no treated and treated with ODPA.

\begin{tabular}{|c|c|c|c|c|c|c|c|c|}
\hline \multirow[t]{3}{*}{ Sample } & \multicolumn{5}{|l|}{ PCFC } & \multicolumn{3}{|l|}{ TGA } \\
\hline & \multicolumn{2}{|c|}{$\operatorname{Tdeg}\left({ }^{\circ} \mathrm{C}\right)$} & \multicolumn{2}{|l|}{ pHRR } & \multirow{2}{*}{$\begin{array}{l}\text { EHC } \\
(\mathrm{kJ} / \mathrm{g})\end{array}$} & \multirow[t]{2}{*}{$\operatorname{Res}_{600}(\%)$} & \multicolumn{2}{|c|}{$\operatorname{Tdeg}\left({ }^{\circ} \mathrm{C}\right)$} \\
\hline & Peak 1 & Peak 2 & Peak 1 & Peak 2 & & & Peak 1 & Peak 2 \\
\hline cel & 370.3 & - & 140.7 & - & 9.6 & 11.1 & 364.2 & - \\
\hline cel/ODPA & 365.3 & - & 179.9 & - & 8.4 & 7.4 & 360.6 & - \\
\hline xyl & 251.6 & 380.8 & 34.7 & 47.6 & 6.3 & 28.8 & 244.8 & 298.1 \\
\hline xyl/ODPA & 245.2 & 294.0 & 43.7 & -39.1 & 7.3 & 27.4 & 244.0 & 294.0 \\
\hline lig & 349.6 & - & 36.4 & - & 9.9 & 54.9 & 371.8 & - \\
\hline lig/ODPA & 375.4 & 350.3 & 30.4 & 38.9 & 13.5 & 50.8 & 516.7 & - \\
\hline
\end{tabular}


To estimate the quantity of ODPA grafted onto flax fibres, theoretical PCFC curves were plotted using the mixing rule (Fig. 3). The $\mathrm{Tfl} / 2.5 \% O D P A$ curve fits well with the experimental curve between 450 to $500^{\circ} \mathrm{C}$. However, for higher temperatures, a deviation is observed. This difference is indicative of an interaction between the fibres and the treatment agent. To give a better estimation of grafted ODPA, the mixing rule was used to fit the effective heat of combustion (EHC) (Table 4). The effective heat of combustion (EHC) of ODPA is $34.3 \mathrm{~kJ} / \mathrm{g}$ while the EHC of flax is only $9.5 \mathrm{~kJ} / \mathrm{g}$. Tfl/ODPA exhibits an experimental EHC of $10.6 \mathrm{~kJ} / \mathrm{g}$. Thus, the mixing rule (Eq. (1)) gives an ODPA amount of $4.4 \mathrm{wt} . \%$.

$\% \mathrm{ODPA}=\frac{\mathrm{EHC}(\mathrm{Tfl} / \mathrm{ODPA})-\mathrm{EHC}(\mathrm{Tfl})}{\mathrm{EHC}(\mathrm{ODPA})-\mathrm{EHC}(\mathrm{Tfl})}$

It should be reminded that $10 \mathrm{wt}$.\% ODPA was added to the fibre during the treatment procedure. Therefore only a part of ODPA was grafted onto the fibres.

In Py-GC/MS, the pyrolytic decomposition of alkyl chains $\left(\mathrm{C}_{18} \mathrm{H}_{37}-\right.$ or $\left.\mathrm{C}_{17} \mathrm{H}_{35}\right)$ is similar to that of low-density polyethylene (LDPE) polymer chains; and the fragmentation occurs through a random scission mechanism that results in the formation of smaller chain fragments of various lengths [28]. In extracted ion chromatograms (EIC) a succession of peaks appeared at the same retention time. Fig. 4 shows the EIC at $m / z 56$ of the ODPA, Tfl/ODPA and Tfl samples after pyrolysis at $900^{\circ} \mathrm{C}$. Similarly to pure ODPA, the EIC at $m / z 56$ of Tfl/ODPA highlights a series of peaks that are assigned to the decomposition products of the alkyl chain of the ODPA molecule. Hence, ODPA possesses an easy recognizable fingerprint in Py-GC/MS that proves its chemical grafting on the flax fibre.

To verify the bonding strength between the flax fibres and the ODPA molecule, a soxhlet extraction procedure with ethanol was performed during $24 \mathrm{~h}$. The ODPA presence on fibres was confirmed after this treatment by a Py-GC/MS analysis (Fig. 4). The chromatogram of the Tfl/ODPAsox sample after the extraction procedure shows the presence of the alkyl chain marker. This result proves that there is a strong linkage between the phosphonated molecule and the flax fibres surface. It is believed that the phosphonic acid functions of the ODPA molecules react with hydroxyl functions available at the fibres surface by phosphorylation creating a covalent $\mathrm{P}-\mathrm{O}-\mathrm{C}$ bond.

\subsection{Covalent bonding of ODPA on flax fibre ( ${ }^{31} P$ NMR)}

The ${ }^{31} \mathrm{P}$ solid-state NMR spectra (Fig. 5), reveal the presence of phosphorus atoms in the Tfl/ODPA sample. These analyses also show an evolution between spectra of the ODPA molecule and Tfl/ODPA sample. ${ }^{31} \mathrm{P}$ chemical shifts are sensitive to variations in the $\mathrm{O}-\mathrm{P}-\mathrm{O}$ bond angle as well as to the electronegativity of the nearest atoms. The peaks of the Tfl/ODPA sample are shifted and indicated a strong interaction between the ODPA headgroup and the flax fibres. Similar ${ }^{31} \mathrm{P}$ resonance shifts have been observed in studies where phosphonic acids were used to modify surfaces of mineral fillers like $\mathrm{SnO}_{2}$ [29] and halloysite [30]. Based on these papers, the shifts have been attributed to the formation

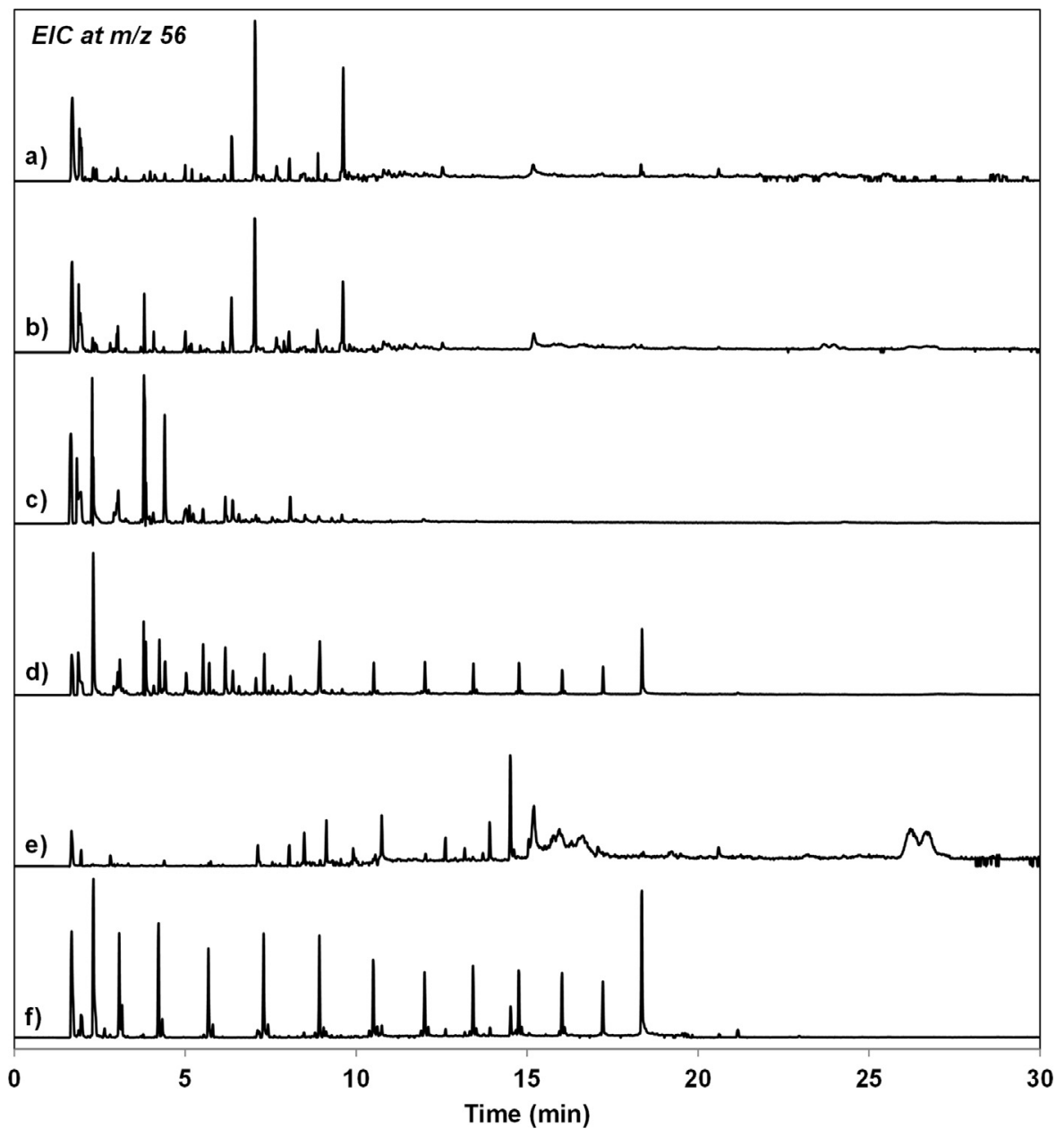

Fig. 8. EIC at $m / z 56$ of pyrograms of (a) cellulose, (b) cel/ODPA, (c) xylan, (d) xyl/ODPA, (e) lignin and (f) lig/ODPA samples. 
of phosphonate covalent bonds obtained by a reaction between ODPA and the hydroxyl groups of the flax fibres surface.

\subsection{Amount of grafted ODPA on flax fibres (elemental analysis)}

Elemental analysis was carried out on Tfl, Tfl/ODPA and Tfl/ODPAsox to confirm the presence of phosphorus element after the ODPA treatment (Table 5). The results prove that the phosphorus was grafted on the fibre. After soxhlet extraction, the phosphorus concentration decreases from 0.52 to $0.40 \mathrm{wt}$.\%. This decrease could be due to the elimination of non-grafted ODPA molecules and to a lesser degree to the degradation of the fibre by the ethanol washing. These results validate the very good efficiency of the ODPA grafting with approximately $5.6 \mathrm{wt} . \%$ of the phosphonated agent remaining on the fibres after treatment. This value is in consistency with the value calculated from the PCFC results.

In the chosen soft conditions, the hydroxyl groups available at flax fibre surface should react with the phosphonic acid function by phosphorylation. To validate this hypothesis, the grafting of dimethyl(octadecyl)phosphonate (DMODP) on Tfl was attempted. No fingerprint relative to the presence of the fatty chain of the DMODP was observed in Py-GC/MS analysis. Thus, it was concluded that the acidic form is required to achieve grafting. The last part of this work is devoted to the reactivity of the phosphonic acid function with the main components of the fibre.

\subsection{Localization of the ODPA treatment on the flax fibre} (SEM/EDX and cellulose, xylan and lignin modification)

The EDX cartography of carbon and phosphorus elements was performed on Tfl and Tfl/ODPA samples to determine the localization of the chemical treatment on the fibre (Fig. 6). The EDX cartography of Tfl showed the absence of any phosphorus element before treatment. On the contrary, the presence of phosphorus is clearly observed after ODPA treatment. The SEM image of the Tfl/ODPA sample shows that the phosphonated zones are mainly surrounding the flax fibre. The micrograph of the Tfl sample in Fig. 6 highlights the action of the pretreatment on the fibre and particularly the separation of bundle fibres. This pretreatment increases the surface available for the grafting of the ODPA molecules. The EDX cartography of Tfl/ODPAsox extraction still shows the presence of the phosphorus element.

Flax fibres are composed of different structural elements (crust, elementary fibres...) and different molecules or macromolecules [31]. Cellulose, hemicelluloses and lignin are the main components of the fibres (Table 2). These components contain hydroxyl functions of different nature, which may allow the ODPA grafting. Cellulose contains only aliphatic hydroxyl functions, whereas xylan [32] and lignin contain both aromatic and aliphatic hydroxyl functions. To better understand the interaction between ODPA and the hydroxyl groups of flax fibres, ODPA grafting procedure was attempted on cellulose (cel), organosolv lignin (lig) and xylan (xyl), which is the main component of hemicelluloses [32]. The same protocol as for flax fibres was used with these three components.

The ODPA molecule was identified using PCFC by the presence of a peak ranging from 430 to $600{ }^{\circ} \mathrm{C}$ only for the lig/ODPA and xyl/ODPA samples (Fig. $7 \mathrm{~b}$ ). This peak presence is significant for lig/ODPA and seems to correspond to a high rate of grafting (Figs. 2 and 7 and Table 6). For the xyl/ODPA sample, the second peak is more attenuated and should correspond to a lower amount of grafting. To quantify the ODPA grafting, the effective heat of combustion was determined, and the grafted ODPA percentage was calculated using the above mentioned mixing rule (Eq. (1)). The EHC of lig/ODPA is $13.5 \mathrm{~kJ} / \mathrm{g}$, which corresponds to $14.7 \mathrm{wt} . \%$ of grafted ODPA, while the EHC of xyl/ODPA is $7.3 \mathrm{~kJ} / \mathrm{g}$

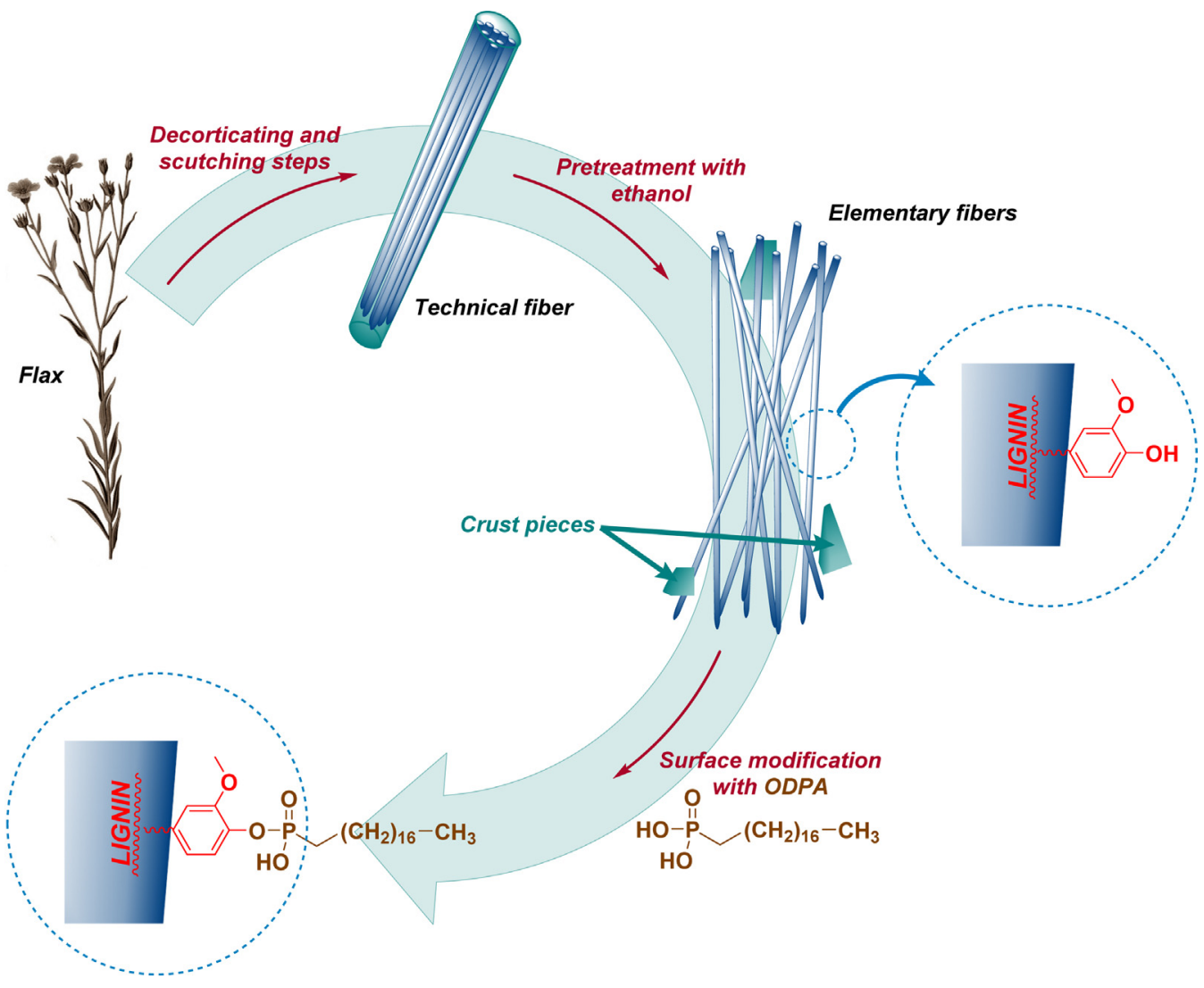

Fig. 9. Schematic representation of the lignin treated with ODPA. 
which corresponds to $3.6 \mathrm{wt}$.\% of grafted ODPA grafting. The grafting of ODPA on lignin is overestimated, because a part of the unfunctionnalized lignin was solubilized during the treatment in ethanol.

The chromatograms obtained for the pure cellulose, xylan and lignin samples (Fig. 8) do not exhibit characteristic peaks in the region between 10 and $15 \mathrm{~min}$. As for Tfl/ODPA, the chromatograms of xyl/ODPA and lig/ODPA exhibit the characteristic peaks which prove the presence of ODPA. Thus, these results are consistent with those obtained by PCFC, and prove that - in our soft conditions - ODPA was grafted only on the xylan and lignin hydroxyls groups. Consequently, the lignin, due to aromatic functions is the component of the flax fibres, that exhibits the best reactivity with the phosphonic function (Fig. 9).

\section{Conclusion}

In this study, the surface modification of flax fibres has been performed, in mild conditions, using ODPA acid as grafting agent. The occurrence and extent of grafting has been highlighted using a non common set of pyrolysis techniques: TGA, PCFC, Py-GC/MS. This method has been corroborated by analytical techniques such as ${ }^{31} \mathrm{P}$ NMR, EDX and SEM observation. The phosphonic acid moiety of ODPA was found to react by phosphorylation with hydroxyl groups of the lignocellulosic fibre, leading to the formation of a covalent bond ( $\mathrm{C}-\mathrm{O}-\mathrm{P}$ linkage). PCFC and elemental analysis give consistent results enabling to affirm that approximately $5 \mathrm{wt} . \%$ of ODPA was grafted onto flax. Phosphorus was observed to be localized at the perimeter of the flax fibres indicating that phosphorylation occurs at the outer surface of fibres. Finally, it was found that, in the chosen conditions of treatment, the phosphonic acid moiety may preferentially react with aromatic hydroxyl groups (from lignin and xylan) than with aliphatic hydroxyl groups (from cellulose and xylan). These first results draw interesting perspectives to incorporate the treated fibres in non polar polymer matrices and to bring new functional properties to flax fibres by grafting more complex molecules bearing a phosphonic acid moiety.

\section{Acknowledgments}

We are grateful to the Institut des Biomolecules Max Mousseron (Université Montpellier II) for the solid state ${ }^{31} \mathrm{P}$ RMN analysis and the elemental analysis of carbon, oxygen and hydrogen and to the Service Central d'Analyse of CNRS (Solaize) for the elemental analysis of phosphorus. We are grateful to Centre de Mise en Forme des Matériaux (CEMEF-Mines ParisTech at Sophia Antipolis, France) for donating lignin organosolv.

\section{References}

[1] A.K. Bledzki, J. Gassan, S. Theis, Wood-filled thermopastic composites, Mechanics of Composite Materials 34 (1998) 563-568.

[2] G. Cantero, A. Arbelaiz, R. Llano-Ponte, I. Mondragon, Effects of fibre treatment on wettability and mechanical behaviour of flax/polypropylene composites, Composites Science and Technology 63 (2003) 1247-1254

[3] M.N. Belgacem, A. Gandini, The surface modification of cellulose fibres for use as reinforcing elements in composite materials, Composite Interfaces 12 (2005) $41-75$.

[4] Y. Xie, C.A.S. Hill, Z. Xiao, H. Militz, C. Mai, Silane coupling agents used for natural fiber/polymer composites: a review, Composite Part A: Applied Science 41 (2010) 806-819.

[5] E. Takács, L. Wojnarovits, C. Földvary, P. Hargittai, J. Borsa, I. Sajo, Effect of combined gamma-irradiation and alkali treatment on cotton-cellulose, Radiation Physics and Chemistry 57 (2000) 399-403.
[6] Y.H. Han, S.O. Han, D. Cho, H.-I. Kim, Kenaf/polypropylene biocomposites: effects of electron beam irradiation and alkali treatment on kenaf natural fibers, Composite Interfaces 14 (2007) 559-578.

[7] M. Ragoubi, B. George, S. Molina, D. Bienaimé, A. Merlin, J.-M. Hiver, A. Dahoun, Effect of corona discharge treatment on mechanical and thermal properties of composites based on miscanthus fibres and polylactic acid or polypropylene matrix, Composites Part A: Applied Science 43 (2012) 675-685.

[8] A. Baltazar-y-Jimenez, M. Bistritz, E. Schulz, A. Bismarck, Atmospheric air pressure plasma treatment of lignocellulosic fibres: impact on mechanical properties and adhesion to cellulose acetate butyrate, Composites Science and Technology 68 (2008) 215-227.

[9] S.V. Prasad, C. Pavithran, P.K. Rohatgi, Alkali treatment of coir fibres for coirpolyester composites, Journal of Materials Science 18 (1983) 1443-1454.

[10] S. Mishra, M. Misra, S.S. Tripathy, S.K. Nayak, a.K. Mohanty, Graft copolymerization of acrylonitrile on chemically modified sisal fibers, Macromolecular Materials and Engineering 286 (2001) 107-113.

[11] M.N. Belgacem, A. Gandini, Natural fiber-surface modification and characterisation, in: S. Thomas, L.A. Pothan (Eds.), Natural Fibre Reinforced Polymer Composites from Macro to Nanoscale, Edition des Archives Contemporaines, 2009, pp. 14-46.

[12] J. George, M.S. Sreekala, S. Thomas, A review on interface modification and characterization of natural fiber reinforced plastic composites, Polymer Engineering \& Science 41 (2001) 1471-1485.

[13] E.S. Medeiros, P.A. Sreekumar, K. Joseph, Role of interface in lignocelluloseic fiber reinforced polymer composites, in: S. Thomas, L.A. Pothan (Eds.), Natural Fibre Reinforced Polymer Composites from Macro to Nanoscale, Edition des Archives Contemporaines, 2009, pp. 270-314.

[14] N.E. Zafeiropoulos, P.E. Vickers, C.A. Baillie, An experimental investigation of modified and unmodified flax fibres with XPS, Polymer 8 (2003) 3903-3914.

[15] Z. Li, W. Zhang, X. Wang, Y. Mai, Y. Zhang, Surface modification of ultra high molecular weight polyethylene fibers via the sequential photoinduced graft polymerization, Applied Surface Science 257 (2011) 7600-7608.

[16] I. Mohammed-Ziegler, I. Tánczos, Z. Hórvölgyi, B. Agoston, Water-repellent acylated and silylated wood samples and their surface analytical characterization, Colloids and Surfaces A: Physicochemical and Engineering Aspects 319 (2008) 204-212.

[17] D. Plackett, K. Jankova, H. Egsgaard, S. Hvilsted, Modification of jute fibers with polystyrene via atom transfer radical polymerization, Biomacromolecules 6 (2005) 2474-2484

[18] M. Abdelmouleh, S. Boufi, M. Belgacem, A. Dufresne, Short natural-fibre reinforced polyethylene and natural rubber composites: effect of silane coupling agents and fibres loading, Composites Science and Technology 67 (2007) 1627-1639.

[19] C. Baley, F. Busnel, Y. Grohens, O. Sire, Influence of chemical treatments on surface properties and adhesion of flax fibre-polyester resin, Composites Part A: Applied Science 37 (2006) 1626-1637.

[20] V.A. Alvarez, Wettability and AFM studies of natural fibres and their composites in: S. Thomas, L.A. Pothan (Eds.), Natural Fibre Reinforced Polymer Composites from Macro to Nanoscale, Edition des Archives Contemporaines, 2009, pp. 417-445.

[21] A. Coupas, H. Gauthier, R. Gauthier, V. Cedex, Inverse gas chromatography as tool to characterize ligno-cellulosic fibers modified for composite applications, Polymer Comporsites 19 (1998) 280-286.

[22] N. Cordeiro, C. Gouveia, G.O. Moraes, S.C. Amico, Natural fibers characterization by inverse gas chromatography, Carbohydrate Polymers 84 (2011) 110-117.

[23] M. Abdelmouleh, Modification of cellulosic fibres with functionalised silanes: development of surface properties, International Journal of Adhesion and Adhesives 24 (2004) 43-54

[24] M. Castellano, A. Gandini, P. Fabbri, M.N. Belgacem, Modification of cellulose fibres with organosilanes: under what conditions does coupling occur? Journal of Colloid and Interface Science 273 (2004) 505-511.

[25] K.C. Manikandan Nair, S. Thomas, G. Groeninck, Thermal and dynamic mechanical analysis of polystyrene composites reinforced with short sisal fibres, Composites Science and Technology 61 (2001) 2519-2529.

[26] R. Lyon, N.R. Walters, Pyrolysis combustion flow calorimetry, Journal of Analytical Applied Pyrolysis 71 (2004) 27-46.

[27] C. Baley, Analysis of the flax fibres tensile behaviour and analysis of the tensile stiffness increase, Composites Part A: Applied Science 33 (2002) 939-948.

[28] D.P. Serrano, J. Aguado, J.M. Escola, J.M. Rodríguez, G. San Miguel, An investigation into the catalytic cracking of LDPE using Py-GC/MS, Journal of Analytical and Applied Pyrolysis 74 (2005) 370-378.

[29] G.P. Holland, R. Sharma, J.O. Agola, S. Amin, V.C. Solomon, P. Singh, et al., NMR characterization of phosphonic acid capped $\mathrm{SnO}_{2}$ nanoparticles, Chemistry of Materials 19 (2007) 2519-2526.

[30] W.O. Yah, A. Takahara, Y.M. Lvov, Selective modification of halloysite lumen with octadecylphosphonic acid: new inorganic tubular micelle, Journal of the American Chemical Society 134 (2011) 1853-1859.

[31] I. Kögel-Knaber, The macromolecular organic composition of plant and microbial residues as inputs to soil organic matter, Soil Biology \& Biochemistry 34 (2002) 139-162.

[32] D. Dodd, I.K.O. Cann, Enzymatic deconstruction of xylan for biofuel production, Global Change Biology Bioenergy 1 (2009) 2-17. 